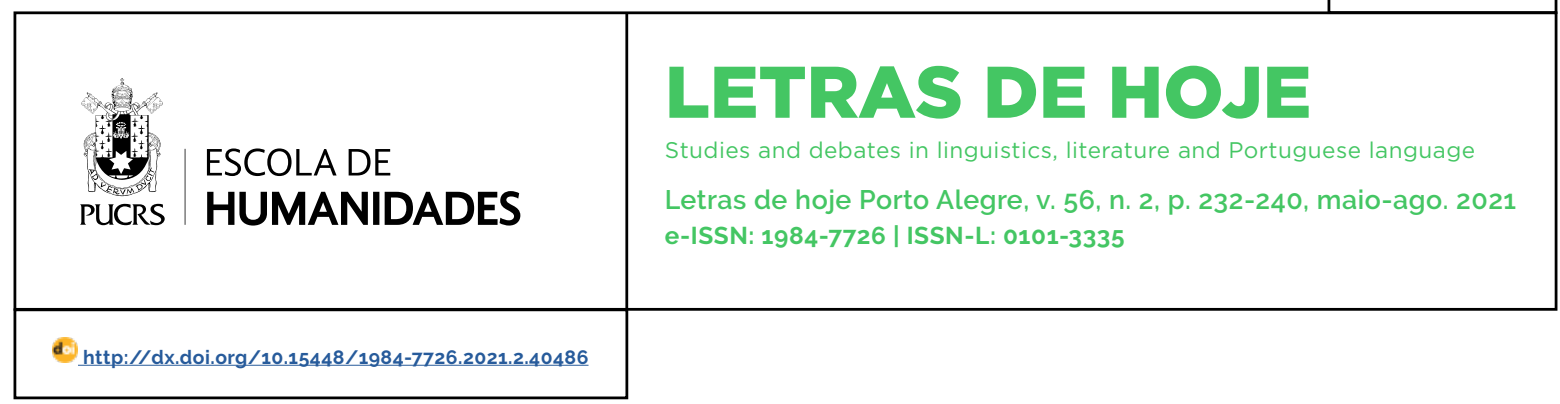

SEÇÃO: O CONTO BRASILEIRO CONTEMPORÂNEO DE AUTORIA FEMININA

\title{
Análise da categoria violência de gênero na obra Insubmissas Lágrimas de Mulheres, de Conceição Evaristo
}

\author{
Analysis of the gender violence category in the book Insubmissas Lágrimas de \\ Mulheres, by Conceição Evaristo \\ Análisis de la categoria violencia de género en la obra Insubmissas Lágrimas de \\ Mulheres, de Conceição Evaristo
}

\section{Franciane Conceição da Silva ${ }^{1}$ orcid.org/0000-0003-3035-5315} francyebano14@hotmail.com

\author{
Yve Almeida Leão ${ }^{1}$ \\ orcid.org/0000-0002-2404-8426 \\ yve_leao@yahoo.com.br
}

Recebido em: 25 mar. 2021. Aprovado em: 2 ago. 2021. Publicado em: 9 nov. 2021
Resumo: O presente trabalho tem como objetivo analisar a categoria violência de gênero a partir do estudo dos contos "Aramides Florença" e "Shirley Paixão", extraídos da obra Insubmissas Lágrimas de Mulheres (2011), da escritora Conceição Evaristo. Procedemos a uma análise de natureza qualitativa, partindo da categoria analítica que envolve dois fenômenos sociais complexos: a violência de gênero e a relação de poder exercida pelos homens sobre as mulheres. A fundamentação teórica é embasada em Pierre Bourdieu (2012) e Heleieth Saffioti (2015). Em uma análise preliminar, observamos que a violência praticada contra as personagens dos contos estudados, vitimas de espancamentos e estupros, representa a objetificação do corpo dessas mulheres e da perpetuação da dominação-exploração feminina, legitimados por um discurso sexista e patriarcal. Palavras-chave: Violência de gênero. Relações de poder. Personagens negras. Literatura Afro-brasileira.

Abstract: The present work aims to analyze the gender violence category from the study of the short stories "Aramides Florence" and "Shirley Paixão", extracted from the book Insubmissas Lágrimas de Mulheres (2011), by the writer Conceição Evaristo. We proceeded to a qualitative analysis, starting from the analytical category that involves two complex social phenomena: gender violence and the power dynamics exercised by men over women. The theoretical basis comes from Pierre Bourdieu (2012) and Heleieth Saffioti (2015) studies. In a preliminary analysis, we observed that the violence practiced against the characters in the studied stories, wich are victms of beatings and rapes, represents the objectification of these women's bodies and the perpetuation of female domination-exploitation, legitimized by a sexist and patriarchal discourse.

Keywords: Gender violence. Power relations. Black characters. Afro-Brazilian literature.

Resumen: El presente trabajo tiene como objetivo analizar la categoria violencia de género a partir del estudio de los cuentos Aramides Florença y Shirley Paixão, extraidos de la obra Insubmissas Lágrimas de Mulheres (2011) de la escritora Conceição Evaristo. Se realizó un análisis cualitativo, partiendo de la categoria analítica que involucra dos fenómenos sociales complejos: la violencia de género y la relación de poder que ejercen los hombres sobre las mujeres. La fundamentación teórica se basa en Pierre Bourdieu (2012) y Heleieth Saffioti (2015). En un análisis preliminar, se observó que la violencia contra los personajes femeninos de los cuentos estudiados, víctimas de palizas y violaciones, representa la objetificación del cuerpo de estas mujeres y la perpetuación de la dominación-explotación femenina, legitimadas por un discurso sexista y patriarcal. Palabras clave: Violencia de género. Relaciones de poder. Personajes femeninos negros. Literatura Afrobrasileña. 


\section{Introdução}

Nos dias atuais, quando nos referimos à literatura de autoria feminina no Brasil, o nome de Conceição Evaristo surge como uma das principais referências. Nascida em 29 de novembro de 1946, na cidade Belo Horizonte, no estado de Minas Gerais, Conceição Evaristo começou a escrever ainda na juventude, mas só teve o primeiro texto publicado em 1990, nos Cadernos Negros, ${ }^{2}$ quando já tinha 44 anos de idade. Depois, lançou os romances Ponciá Vicêncio (2003), Becos da Memória (2006) e Canções para ninar menino grande (2018). Em 2008, a autora lançou Poemas da recordação e outros movimentos, o seu único livro de poesias até agora. Além dessas obras, Evaristo escreveu três coletâneas de contos: Insubmissas lágrimas de mulheres (2011), Olhos D'água (2015), Histórias de leves enganos e parecenças (2016). Seus textos poéticos e ficcionais, aqui se destacando os contos,

Equilibram-se entre a afirmação e a negação, entre a denúncia e a celebração da vida, entre o nascimento e a morte [...]. Sem quaisquer idealizações, são recriadas com firmeza e talento as duras condições enfrentadas pela comunidade afro-brasileira (GOMES, 2016, p. 236).

Poeta, contista, romancista, ensaísta, Conceição Evaristo é uma das vozes mais importantes da Literatura Brasileira Contemporânea. Ganhadora do Prêmio Jabuti em 2015, com o livro Olhos D'água, nasceu em uma familia de mulheres negras periféricas que sempre foram suas grandes referências. E, por entender desde muito cedo a condição histórica de silenciamento dessas mulheres, busca, com o movimento da sua escrita, criar condições para que essas vozes silenciadas sejam ouvidas.

Neste trabalho, vamos refletir a respeito da obra Insubmissas Lágrimas de Mulheres (2011). Insubmissas reúne 13 contos que abordam experiências vividas por mulheres negras de contextos diversos. Todos os contos são intitulados com os nomes das personagens que são protagonistas da história a ser narrada. Essas personagens que nomeiam os contos, como já anunciado no título da obra, são mulheres insubmissas que se rebelam contra a misoginia, o machismo, o racismo e todas as manifestações de violências e opressões. Os contos de Insubmissas Lágrimas de Mulheres narram vivências de personagens negras que contam as suas histórias para uma narradora-personagem. Nesse processo, a ouvinte curiosa escuta atentamente as histórias que lhes são reveladas, compartilha essas narrativas com o(a) leitor(a) e registra também as suas impressões, dando testemunho do que ouviu e sentiu. As relações de poder, a dominação-exploração das mulheres pelos homens é um tema que perpassa quase todos os contos da obra em análise. Essa relação de poder, dentro da perspectiva de gênero, se manifesta através de diferentes atos de violência contra os corpos femininos: assédio moral, estupro, espancamento, lesbofobia, violência psicológica, violência patrimonial, dentre outras. Conceição Evaristo constrói narrativas que se confundem com a realidade, pois, apesar da transformação desses temas em ficção, mesmo que a arte apresente uma autonomia, não deixa de ter um vinculo com o contexto das experiências reais de tantas mulheres.

O desenvolvimento da presente análise se restringirá aos contos "Aramides Florença" e "Shirley Paixão". Não obstante a subjugação de todas as mulheres dos contos a partir da sua condição de gênero, nas duas narrativas que selecionamos para análise, a dominação masculina e a violência advinda da discriminação de gênero se fazem presentes a partir do momento em que o corpo da mulher é tomado como objeto, como propriedade masculina, dentro do contexto doméstico.

No conto "Aramides Florença", a narradora chega à casa da protagonista e a encontra com o seu filho, de quase um ano, nos braços. Nesse momento, a narradora percebe a forte ligação que existe entre a mãe e o filho. Aramides conta para a interlocutora como conheceu o amor da

\footnotetext{
O primeiro volume dos Cadernos Negros foi publicado no ano de 1978, contemplando a produção de oito poetas. A partir de 1980 autores que organizavam a antologia criaram o grupo Quilombhoje, que desde então é responsável pela edição e publicação dos Cadernos. É importante ressaltar que, desde a sua primeira edição, em 1978, os Cadernos Negros são publicados ininterruptamente, revezando entre coletâneas de poemas e contos.
} 
sua vida, como foram felizes durante o namoro e quase toda a sua gestação. Todavia, essa tranquilidade é quebrada já nos últimos meses de gravidez da protagonista, quando se iniciam os atos violentos de seu companheiro.

Em "Shirley Paixão", conhecemos a história da protagonista contada por ela mesma, predominantemente em primeira pessoa. Shirley, com duas filhas, apaixona-se por um homem viúvo, pai de três meninas. Indo viver maritalmente com o homem, Shirley revela que se tornou mãe para além do vínculo sanguíneo das três enteadas. Enquanto a mulher, em um gesto nobre de afeto, cria uma irmandade entre ela e todas as filhas, o homem da casa, pai das meninas, começa a agir de maneira cada vez mais violenta.

A presença da violência de gênero e da relação de poder entre homem e mulher é notável nos dois contos. Essa violência está inserida em uma estrutura de poder onde um é submisso a outro em uma relação de dominação eficaz desse corpo, no caso, do corpo feminino. A visão do homem é objetificadora, como se o corpo feminino coisa dele fosse. Esse homem, munido pelo sentimento de posse, no conto "Aramides Florença" se sente no direito de violentar a mulher no puerpério; já no conto "Shirley Paixão", o macho possessivo, violenta, de maneira impiedosa, a própria filha.

Em "Aramides Florença", a dominação masculina se dá através da dor física, da subjugação da mulher pelo homem que a tem como seu objeto. O ciúme do marido em relação ao filho é a causa da violência de gênero retratada no conto. No momento em que a mulher se torna mãe, ela deixa de ser objeto do homem para se dedicar ao filho. Em "Shirley Paixão", o ódio do homem e o sentimento de posse são intensificados, pois ele não se conforma com a irmandade construida entre as mulheres da casa, mãe e filhas. A união das mulheres ameaça o poder do macho possessivo. Nesse território de dominação, em ambos os contos, se estabelece que o chefe, via de regra, é um homem. Essa realidade, quando subvertida, gera a intimidação, a atemorização e a gradação da violência.

\section{Fundamentação teórica}

A análise da categoria temática violência de gênero realiza-se a partir das teorias trazidas por Heleieth Saffioti (2015) e Pierre Bourdieu (2012). A autora concebe o conceito de violência como a quebra da integridade física de uma pessoa na esfera psíquica, sexual e/ou moral. Já o autor reflete acerca da violência simbólica, invisivel, que perpassa as camadas sociais, e é reproduzida e construída historicamente por agentes específicos.

Saffioti (2015) afirma que gênero é um conceito vasto, não se resumindo apenas a uma categoria de análise, mas que também deve ser entendido como uma categoria histórica:

\begin{abstract}
Enquanto categoria histórica, o gênero pode ser concebido em várias instâncias: como aparelho semiótico (Lauretis, 1987); como símbolos culturais evocadores de representações, conceitos normativos como grade de interpretação de significados, organizações e instituições sociais, identidade subjetiva (Scott, 1988); como divisões e atribuições assimétricas de característicos e potencialidades (Flax, 1987); como, numa certa instância, uma gramática sexual, regulando não apenas relações homem-mulher, mas também relações homem-homem e relações mulher-mulher (Saffioti, 1992, 1997-b, Saffioti e Akmeida, 1995), etc. cada feminista enfatiza determinado aspecto do gênero, havendo um campo, ainda que limitado, de consenso: o gênero é a construção social do masculino e do feminino (SAFFIOTI, 2015, p. 47).
\end{abstract}

Para além de uma categoria de análise, entender gênero em seu aspecto histórico é considerá-lo como processo, é entender que, como outros fenômenos sociais, ele se transforma com o avançar da história. Bourdieu (2012) também reflete acerca da perpetuação das estruturas da divisão sexual e dos princípios de divisão correspondentes, afirmando que esse processo de transformação do arbitrário cultural em natural, essa soberania masculina, dispensa justificação. Ademais, não é só a mulher que é alvo dessa representação dominante, mas também o homem. O teórico francês traz o conceito de habitus viril, sempre que a masculinidade é colocada à prova. Segundo o autor, ao homem se impõe ser másculo, assumir o papel de provedor, de protetor, de macho. O homem precisa adotar uma postura de "dever-ser" também naturalizada, construída 
e arraigada no construto social. Bourdieu (2012) também considera que o gênero não pode se dissociar do momento histórico e de seus agentes e instituições que contribuiram para a construção dos conceitos da relação entre homem e mulher, da dominação masculina e do patriarcado.

Nesse sentido, o autor francês defende que a perpetuação das estruturas da divisão sexual e dos princípios dessa divisão correspondentes leva a uma eternização dos costumes engendrada pelas instituições sociais de uma forma macro (igreja, escola, Estado), e de uma forma micro dentro da esfera doméstica, não se restringindo à dominação-exploração ao espaço familiar, mas se perpetuando também nas instâncias maiores da sociedade.

Essa dominação do homem sobre a mulher é a base para a construção da desigualdade na relação homem-mulher. Saffioti (2015) afirma que essa desigualdade pode ser construida. Ela é legitimada pelas estruturas de poder e pela tradição cultural. É o que Bourdieu (2012, p. 8) chama de "transformação do arbitrário cultural em natural": as relações de dominação se perenizam e o modo como ela pode se dar é através de uma violência simbólica, invisível.

Na concepção de Saffioti, um conceito indissociável para se pensar a violência de gênero é o de patriarcado. Ela insere o conceito de patriarcado em uma dimensão histórica, definindo-o "como um pacto masculino para garantir a opressão de mulheres" (SAFFIOTI, 2015, p. 111). Para ela, os homens asseguram, através do poder de dominação-exploração, os meios necessários à produção diária e reprodução da vida:

Neste regime, as mulheres são objetos de satisfação sexual dos homens, reprodutoras de herdeiros, de força de trabalho e de novas reprodutoras. Diferentemente dos homens como categoria social, a sujeição das mulheres, também como grupo, envolve prestação de serviços sexuais a seus dominadores. Esta soma/mescla de dominação e exploração é aqui entendida como opressão (SAFFIOTI, 2015, p. 112).

A autora disserta também sobre a presença desse patriarcado nos campos profissional, intelectual, educacional. Todavia, no presente trabalho, utilizaremos o conceito de patriarcado no campo sexual, no controle da sexualidade da mulher.

Apesar dessa amplitude do conceito, podemos perceber um consenso quanto a ser o gênero uma construção social do masculino e do feminino. Dessa forma, por ser o tema violência de gênero bastante amplo, faz-se necessário indicar o enfoque que analisaremos no presente trabalho: violência de gênero com foco na relação de poder exercida pelo homem sobre a mulher. Nos dois contos que selecionamos para analisar, a violência simbólica não é deixada de lado, mas as violências física e sexual serão mais abordadas, uma vez que acreditamos que estas são produtos daquela.

Esse processo de dominação e de efeitos do patriarcado na vida das mulheres se dá cotidianamente. O poder circula em sociedade, nas e pelas relações sociais. Foucault (1981) pensa o poder não como algo que possa ser apropriado, como se um objeto fosse, mas, "em outros termos, o poder não se aplica aos indivíduos, passa por eles" (FOUCAULT, 1981, p. 163). Nesse sentido, percebe-se que a construção das estruturas de poder a partir do sexismo é muito desigual. As mulheres são socializadas a terem seus corpos docilizados, apaziguados, afastadas do exercício do poder; enquanto os homens são estimulados a desenvolverem a razão, a coragem, a conduta agressiva. Essa pode ser uma das raízes do fenômeno da violência de gênero.

\section{Análise crítica}

Como já exposto anteriormente, o corpus selecionado para esta pesquisa são os contos "Aramides Florença" e "Shirley Paixão", extraídos da obra Insubmissas Lágrimas de Mulheres (2016), de Conceição Evaristo.

No conto "Aramides Florença", a narrativa se inicia em primeira pessoa, quando a narradora personagem chega à casa de Aramides, e logo conhece o seu filho, Emildes Florença. Nesse primeiro contato, a narradora já percebe a forte ligação existente entre mãe e filho, tomando conhecimento sobre a partida do pai da criança. Atenta aos movimentos do pequeno no colo da mãe, a narradora observa: 
Teria a criança, tão novinha, - pensei mais tarde, quando ouvi a história de Aramides Florença, - se rejubilado também com a partida do pai? Só a mãe, só a mulher sozinha, lhe bastava? [...]. Aramides Florença buscava ser o alimento do filho. E, literalmente, era (EVARISTO, 2016, p. 10).

Após o primeiro contato entre a protagonista e a narradora, a mãe de Emildes começa a contar a sua história. Ela fala da felicidade inicial do relacionamento entre ela e o pai da criança, tendo idealizado aquele "homem certo que chegaria para ser o seu companheiro e pai de seu filho" (EVARISTO, 2016, p. 11). A mulher fala da alegria do tempo de namoro e da plenitude dela e do companheiro quando os dois "grávidos" foram felizes.

Todavia, "um dia algo [...] inaugurou uma perturbação entre os dois" (EVARISTO, 2016, p. 13). Acontece o primeiro ato violento do homem contra a mulher, ainda grávida: uma lâmina de barbear deixada em cima da cama de Aramides fere seu corpo: "com dificuldades para se erguer, gritou de dor. Um filete de sangue escorria de um dos lados de seu ventre" (EVARISTO, 2016, p. 13). Tendo deixado de propósito o objeto sobre a cama do casal, o marido finge não saber como aquilo havia ocorrido.

Depois dessa primeira situação, "outro fato veio causar mais uma inquietação, e um ligeiro, ligeirissimo mal-estar na confiança que Aramides depositava em seu homem" (EVARISTO, 2016, p. 13. grifo nosso). Desta vez, de maneira direta, o marido violenta o corpo da esposa grávida:

Pelo espelho, viu o seu homem se aproximar cautelosamente. Adivinhou o abraço que dele receberia por trás. Fechou os olhos e gozou antecipadamente o carinho das mãos do companheiro em sua barriga. Só que, nesse instante, gritou de dor. Ele, que pouco fumava, e principalmente se estivesse na presença dela, acabara de abraçá-la com o cigarro aceso entre os dedos. Foi um gesto tão rápido e tão violento que o cigarro foi macerado e apagado no ventre de Aramides. Um ligeiro odor de carne queimada invadiu o ar. Por um infimo momento, ela teve a sensação de que o gesto dele tinha sido voluntário (EVARISTO, 2016, p. 14, grifo nosso).

Após esses atos violentos antes do nascimento da criança, depois que ela nasceu, Aramides pareceu se esquecer de tudo, pois a solicitude do marido era uma constante no seu dia a dia. Todavia, duas semanas depois do nascimento do filho, "um medo começou a rondar o coração e o corpo de Aramides" (EVARISTO, 2016, p. 17).

[...] o homem, olhando para o filho no berço, perguntou a Aramides, quando ela novamente seria dele, só dele. A indagação the pareceu tão despropositada, que ela não conseguiu responder, embora tenha percebido o tom ciumento da pergunta. Um silêncio sem lugar se instalou entre os dois. Aramides desejou que o bebê acordasse chorando, mas ele ressonava tranquilo. Buscando apaziguar a insegurança do homem, ela se aconchegou a ele, que levantou rispidamente. E foi tão violento o bater da porta, quando ele abandonou o quarto, que o bebê, antes tão em paz, acordou chorando (EVARISTO, 2016, p. 15).

A personagem afirma que cenas semelhantes a essas voltaram a acontecer inúmeras vezes. A parte final do conto é a mais intensa. Na perspectiva da primeira pessoa, a mulher conta a violência brutal praticada contra ela pelo marido:

Estava eu amamentando o meu filho [...] quando o pai de Emildes chegou. De chofre arrancou o menino de meus braços, colocando-o no bercinho sem nenhum cuidado. [...] numa sucessão de gestos violentos, ele me jogou sobre nossa cama, rasgando minhas roupas e tocando violentamente com a boca um dos meus seios que já estava descoberto, no ato de amamentação de meu filho. E, dessa forma, o pai de Emildes me violentou. E, em mim, o que ainda doía um pouco pela passagem de meu filho, de dor aprofundada sofri, sentindo o sangue jorrar. [...] Nunca a boca de um homem, como todo o seu corpo, me causara tanta dor e tanto asco, até então. [...] Esse homem estava me fazendo coisa dele, sem se importar com nada, nem com nosso filho, que chorava no berço ao lado (EVARISTO, 2016, p. 17).

Percebemos que no conto em análise, as agressões se iniciam já na gestação da personagem. A violência percebida no texto se dá na disputa de poder entre o homem e o ser que ainda vai nascer. Saffioti (2015), citando os estudos de Freud, disserta sobre a inveja da maternidade sentida pelos homens. Além disso, a autora reflete sobre o conceito de patriarcado em uma vertente sexual, sendo a dominação dos homens sobre as mulheres uma espécie de direito daqueles sobre o corpo destas:

Isto equivale a dizer que o agente social marido se constitui antes que a figura do pai. Esta se 
encontra atenuada nas sociedades complexas contemporâneas, mas ainda é legitimo afirmar-se que se vive sob a lei do pai. Todavia, a figura forte é a do marido, pois é ela que o contrato social dá à luz. O pátria potestas cedeu espaço, não à mulher, mas aos filhos. O patriarca que ele estava embutido continua vivo como titular do direito sexual (SAFIOTTI, 2015, p. 59, grifo da autora).

No conto "Aramides Florença", a violência não é só fisica, mas também simbólica, pois percebemos que o marido da personagem não se conforma com a chegada de "outro" na relação, sentindo-se preterido pela mulher não ser apenas "sua", comete o estupro contra a mãe do seu próprio filho no puerpério. Essa característica de macho violento e dominador do personagem masculino é acentuada no final do conto, quando Aramides afirma:

E quando ele se levantou com o seu membro murcho e satisfeito, a escorrer o sangue que jorrava de mim, ainda murmurou entre os dentes que não me queria mais, pois eu não havia sido dele, como sempre fora, nos outros momentos de prazer (EVARISTO, 2016, p. 18).

A protagonista do conto é tratada como um objeto, como algo que pode ser usado e descartado, e o corpo feminino é visto pelo homem como uma propriedade a ser conquistada, dominada e abandonada. Esse sentimento de posse é pensado por Bourdieu a partir do sistema simbólico apresentado por ele, justificando a dominação-exploração do homem sobre a mulher dentro dos sistemas patriarcais e fomentado pelas instituições do próprio Estado.

Essa dominação-exploração é incentivada socialmente quando pensamos no habitus (BOURDIEU, 2012), na ideologia eternizada de que o masculino precisa ser forte, viril, agressivo, em detrimento ao feminino doce, sensivel, calmo, passivo, frágil. Assim, essa "organização social de gênero, baseada na virilidade como força-potência-dominação, permite prever que há um desencontro amoroso marcado entre homens e mulheres" (SAFIOTTI, 2015, p. 79).

No conto "Shirley Paixão", a narrativa se inicia com a personagem contando que quase tinha matado o seu ex-companheiro, e que não havia arrependimento algum quanto a esse fato. Ela narra o quanto a vida cumpliciada entre ela, suas duas filhas legitimas e as três filhas dele (tendo ela se tornado mãe de todas) incomodava o homem:

\begin{abstract}
Uma confraria de mulheres. Às vezes, o homem da casa nos acusava, implicando com o nosso estar sempre junto. Nunca me importei com as investidas dele contra a feminina aliança que nos fortalecia. Não sei explicar, mas, em alguns momentos, eu chegava a pensar que estávamos nos fortalecendo para um dia enfrentarmos uma luta. Uma batalha nos esperava e, no centro do combate, o inimigo seria ele (EVARISTO, 2016, p. 28, grifo nosso).
\end{abstract}

Seguindo a narrativa, Shirley fala sobre uma das filhas do companheiro, a mais velha, chamada Seni. Caracteriza-a como a mais calada, desde a morte da sua mãe, a mais tímida, mas a mais cuidadosa com todas as mulheres da casa. O pai não tinha a mínima paciência com a menina, vivia implicando com ela. Ao perceber a dificuldade de relacionamento entre Seni e o pai, Shirley passa a amparar a proteger cada vez mais a enteada.

Aos doze anos, apesar de ser destaque na escola, Seni demonstrava uma mania de perfeição e uma grande autocensura, o que preocupava as professoras. Indagada sobre uma possivel severidade do pai em relação à filha, Shirley afirma que, de fato, o pai implicava muito com Seni, "mas pouco ou nada exigia. Quando se dirigia à menina era sempre para desvalorizá-la constantemente com palavras de deboche" (EVARISTO, 2016, p. 29).

Tendo comentado com o marido sobre essa conversa na escola, a narradora percebe que o homem tem um acesso de raiva, quase chegando a agredir fisicamente a menina. A agressão fisica não ocorre nesse momento porque Shirley consegue afastá-lo delas, gritando para que ele saisse do cômodo da casa onde se encontravam e as deixasse sozinhas, aos prantos e com muito medo. Todavia, poucas horas depois, a violência se concretiza:

Então, puxou violentamente Seni da cama, modificando naquela noite, a maneira silenciosa como ele retirava a filha do quarto e levava aos fundos da casa para machucá-la, como acontecia há anos. Naquela noite, o animal estava tão furioso - afirma Shirley, chorando - que Seni, para a sua salvação, fez do medo, do pavor, coragem. E se irrompeu em prantos e gritos [...]. E avançou sobre Seni, gritando, 
xingando os maiores impropérios, rasgando suas vestes e expondo à nudez aquele corpo ainda meio-menina, violentado diversas vezes por ele, desde quando a mãe dela falecera. [...] Um homem esbravejando, tentando agarrar, possuir, violentar o corpo nu de uma menina, enquanto outras vozes suplicantes, desesperadas, desamparadas, chamavam por socorro. Pediam ajuda ao pai, sem perceberem que ele era o próprio algoz (EVARISTO, 2016, p. 32).

Pela passagem transcrita acima, percebemos que a violência sexual sofrida por Seni vinha sendo perpetrada pelo pai há anos, estando a menina sofrendo os abusos em silêncio. Diante dessa cena, Shirley age em um impulso. Desesperada, a mulher pegou uma barra de ferro que estava no quarto que funcionava como tranca para a janela e golpeou o homem na cabeça. Momentos depois, apareceram vizinhos para ajudar, segurando Shirley, impedindo que ela continuasse a golpear o criminoso.

Shirley e o ex-companheiro são presos. Ela cumpre três anos de pena, sai da cadeia para continuar a vida com as suas filhas, conseguindo contar essa sua história trinta anos depois, orgulhosa, pois "a nossa irmandade, a confraria das mulheres, é agora fortalecida por uma geração de meninas netas que desponta" (EVARISTO, 2016, p. 34).

Assim como em "Aramides Florença", vemos em "Shirley Paixão" a disputa pelo poder e a dominação-exploração por parte do homem, agora sobre a filha, sobre o corpo frágil de uma criança de doze anos, que sofre silenciosamente os abusos sexuais cometidos pelo seu pai.

No início do conto, a personagem sinaliza que a confraria das mulheres, a irmandade, a cumplicidade entre elas, de alguma forma, incomodavam o homem da casa. As mulheres juntas eram fortes, potentes, e, em consequência, ele se enfraquecia, tornava-se impotente, destronado de sua posição de poder. Saffioti (2015) acredita que é nesse sentimento de impotência que a violência acontece:

O poder, como já foi escrito (Saffioti e Almeida, 1995), tem duas faces: a da potência e a da impotência. As mulheres estão familiarizadas com esta última, mas este não é o caso dos homens, acreditando-se que, quando eles perpetram violência, estão sob o efeito da impotência (SAFFIOTI, 2015, p. 54).
A violência sexual cometida pelo pai contra a filha na narrativa já vinha acontecendo há anos. Desde criança, a dominação-exploração do patriarca era sentida pela vítima. A casa, o espaço privado novamente aqui, é o território de dominação. E essa "violência doméstica tem um gênero: o masculino" (WELZER-LANG, 1991 apud SAFFIOTI, 2015, p. 78).

Essa relação social domiciliar é o primeiro modo de regulação, e a criança é a primeira a experimentar essa dominação. Saffioti (2015) afirma, ainda, que "o gênero, a família e o território domiciliar contêm hierarquias, nas quais os homens figuram como dominadores-exploradores e as crianças como os elementos mais dominados-explorados" (SAFFIOTI, 2015, p. 78, grifo da autora).

Dentro desse espaço domiciliar e de relações de poder, Bourdieu (2012) afirma que a família patriarcal é a base da ordem social, uma estrutura dominante familiar, fundamentada na submissão da mulher em relação ao homem, dos adultos sobre as crianças, onde o homem é o dominador, para a perpetuação do habitus:

É, sem dúvida, à família que cabe o papel principal na reprodução da dominação e da visão masculinas; é na familia que se impõe a experiência precoce da divisão sexual do trabalho e da representação legitima dessa divisão, garantida pelo direito e inscrita na linguagem (BOURDIEU, 2012, p. 103).

O conceito de patriarcado, configurado como um tipo hierárquico de relação, representa no conto "Shirley Paixão" uma estrutura de poder baseada na violência, no controle e no medo. Para além disso, a violência sexual praticada pelo pai pode ser entendida como uma faceta desse direito patriarcal, como um direito sexual. Saffioti (2015) reflete que "o agente social marido se constitui antes que a figura do pai" (SAFFIOTI, 2015. p. 59, grifo da autora).

Com a morte da mãe biológica de Seni, o pai inicia os abusos sexuais contra a filha, exercendo esse direito patriarcal, reivindicando o direito sexual da filha como se sua esposa fosse: "O direito sexual ou conjugal estabelece-se antes do direito de paternidade. O poder político do homem assenta-se no direito sexual ou conjugal. 
Assim, a autoridade política do homem já está garantida bem antes de ele se transformar em pai" (SAFFIOTI, 2015, p. 137).

A autora reflete, ainda, sobre a relação entre gênero e sexo. Apesar de o gênero ser construído socialmente, ele não se separa totalmente do sexo, não se reduzindo a este, nem sendo possivel o sexo ser um fenômeno puramente biológico. $\mathrm{O}$ conceito de gênero se sustenta nessa ideologia patriarcal que coloca as mulheres abaixo dos homens na relação de poder:

Não seria o gênero exatamente aquela dimensão da cultura por meio da qual o sexo se expressa? Não é precisamente por meio do gênero que o sexo aparece sempre vinculado ao poder? O estupro não é um ato de poder, independentemente da idade e da beleza da mulher, não estando esta livre de sofrê-lo mesmo aos 98 anos de idade? Não são todos os abusos sexuais atos de poder? (SAFFIOTI, 2015, p. 144).

O que podemos observar nos dois contos em análise na obra Insubmissas Lágrimas de Mulheres é a repetição da violência, da dominação-exploração, das bases do patriarcado sendo colocadas em prática. Todavia, o desfecho das narrativas analisadas, apresenta para nós, leitoras e leitores, uma possibilidade de mudança, uma vez que, apesar das violências físicas e simbólicas sofridas pelas personagens, elas conseguem se desfazer da submissão, festejam a ausência masculina e se fortalecem na maternidade, reagindo a dor, superando-a. Importante ressaltar que nenhum sofrimento deve ser romantizado. Muito menos aquele construído e produzido em um contexto histórico-social de manutenção de poder do patriarcado, para não cairmos no perigo da naturalização/banalização da violência.

Na medida em que as personagens dos contos tomam consciência das violências a que são submetidas, elas se reconhecem como sujeitos e aprendem a (re)agir às agressões. É na sensação física da sujeição que o sujeito descobre a potencialidade da resistência. Dessa forma, Aramides Florença e Shirley Paixão, a partir da constituição e rememoração de suas histórias, conseguem elaborar a dor e o sofrimento impostos aos seus corpos, se libertar dos machos-dominadores, emanciparem-se física e emocionalmente e, acima de tudo, elas conseguem seguir em frente, tornando-se protagonistas de suas próprias histórias.

\section{Considerações finais}

No presente artigo, buscamos refletir sobre a violência de gênero a partir de contos da obra Insubmissas Lágrimas de Mulheres, de autoria de Conceição Evaristo. Importante dizer que várias outras categorias analiticas poderiam ser abordadas neste livro, como raça, maternidade, entre outros temas que podem e devem ser aprofundados em trabalhos posteriores. O recorte feito foi necessário para o alcance do nosso objetivo.

Trouxemos as vozes de autores como Heleieth Saffioti (2015) e Pierre Bourdieu (2012) para elucidar questões, como conceitos de gênero, patriarcado, relação de poder, dominação-exploração, violência física e simbólica, habitus. Apresentar esses aspectos gerais sobre o gênero e a dominação masculina se mostrou necessário para a análise das narrativas.

A dor dos corpos das personagens, que sofreram violência física, sexual e simbólica, foi retratada através da análise dos contos "Aramides Florença" e "Shirley Paixão". A partir dos espancamentos e estupros, percebemos a perpetuação da violência de gênero, legitimada pelo patriarcado machista, racista, misógino e sexista. As inúmeras manifestações de violências, representadas nos contos de Conceição Evaristo, denunciam o processo histórico de objetificação do corpo da mulher para a perpetuação da dominação masculina e da dominação-exploração feminina.

Procuramos mostrar, a partir da análise desses contos, que instituições como a família perpetuam o discurso patriarcal, e como essas explorações materiais e simbólicas são retroalimentadas, reforçam-se, no espaço privado da casa. Quando pensamos no patriarcado como modelo de opressão, entendemos que ele constrói um modelo de mulher submissa ao marido, prestadora de serviços sexuais, e que estaria fora do mundo social, fora da esfera pública, apenas presente na esfera privada. A ocupação dos espaços públicos pelas mulheres é urgente, pois é no social que as 
normas culturais se perpetuam, mas é também aí que podemos alcançar a transformação das bases.

Trazer histórias de mulheres escritas por mulheres é combater o discurso hegemônico de que a história é contada pelos homens e para eles. A literatura tem essa função de abordar assuntos importantes, como a violência de gênero, tão comum no Brasil, que nos convocam a refletir, a combater, a nos posicionar e a agir.

Além disso, refletir sobre gênero nos chama a uma mudança estrutural profunda em nossa sociedade, a questionar os papéis sociais em uma dada cultura, em um conjunto de valores. Contestar, confrontar esses papéis homem/mulher é de suma importância, pois se acreditamos que o feminino é algo que se constrói, o masculino também. A luta contra a violência de gênero deve ser travada por mulheres e homens. O processo de mudança deve ser engendrado por todos. Se só um dos sujeitos mudar, o outro permanecerá mantendo o habitus.

Apesar de serem ficcionais, as histórias de Aramides Florença e Shirley Paixão jogam luz em questões como patriarcado, relações de poder, desumanização, invisibilidade, e, em contrapartida, resistência e superação. Por essa razão, compreendemos o caráter humanizador dos contos de Conceição Evaristo ao aproximar o(a) leitor(a) de graves problemas reais, convidando-os(as) a refletirem sobre eles e movê-los(las) à ação transformadora.

\section{Referências}

BOURDIEU, Pierre. A dominação masculina. 2. ed. Rio de Janeiro: Bertrand Brasil, 2012.

EVARISTO, Conceição. Insubmissas Lágrimas de MuLheres. 2. ed. Rio de Janeiro: Malê, 2016.

FOUCAULT, Michel. Microfisica do Poder. Rio de Janeiro: Graal, 1981

GOMES, Heloísa Toller. Algumas palavras sobre a tessitura poética de Olhos D'água. In: DUARTE, Constância Lima; CÔRTES, Cristiane; PEREIRA, Maria do Rosário Alves. (org.). Escrevivências: identidade, gênero e violência na obra de Conceição Evaristo. Belo Horizonte: Idea, 2016, p235-246.

SAFFIOTI, Heleieth. Gênero, Patriarcado e Violência. 2. ed. São Paulo: Expressão Popular: Fundação Perseu Abramo, 2015

\section{Franciane Conceição da Silva}

Doutora em Literaturas de Lingua Portuguesa pela Pontifícia Universidade Católica de Minas Gerais (PUC-MG), em Belo Horizonte, MG, Brasil; professora do Departamento de Letras Clássicas e Vernáculas (DLCV), da Universidade Federal da Paraíba (UFPB), em João Pessoa, PB, Brasil.

\section{Yve Almeida Leão}

Graduada em Letras Pela Universidade Federal da Paraiba (UFPB), em João Pessoa, PB, Brasil; graduada em Direito pela Universidade Estadual da Paraíba (UEPB), em Campina Grande, PB, Brasil.

\section{Endereço para correspondência}

Franciane Conceição da Silva/ Yve Almeida Leão

Universidade Federal da Paraiba

UFPB-CCHLA- Bloco Humanístico

Departamento de Letras Clássicas e Vernáculas (DLCV)

Campus I - Castelo Branco I, 58051-900

João Pessoa, PB, Brasil

Os textos deste artigo foram revisados pela Poá Comunicação e submetidos para validação das autoras antes da publicação. 